\title{
As Normas Internacionais de Contabilidade: Em Busca por Harmonização nos Fluxos Econômicos Globais
}

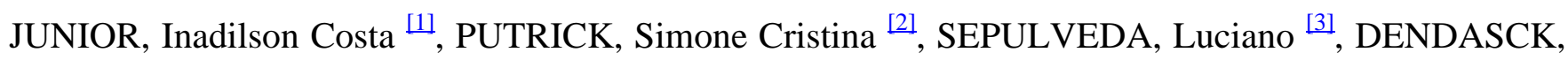
Carla Viana ${ }^{[4]}$

JUNIOR, Inadilson Costa; et.al. As Normas Internacionais de Contabilidade: Em Busca por Harmonização nos Fluxos Econômicos Globais. Revista Científica Multidisciplinar Núcleo do Conhecimento. Ano 03, Ed. 02, Vol. 04, pp. 124-143, Fevereiro de 2018. ISSN: 2448-0959, Link de acesso: https://www.nucleodoconhecimento.com.br/contabilidade/normas-internacionais-contabilidade, DOI: 10.32749/nucleodoconhecimento.com.br/contabilidade/normas-internacionais-contabilidade

\section{RESUMO}

O presente estudo teve como intuito investigar como as normas internacionais de contabilidade podem influenciar na atual conjuntura de mercado global. O tema é relevante, pois o seu conhecimento faz-se importante no cenário globalizado aos usuários de empresas envolvidas que buscam eficiência no atual modelo econômico. O direcionamento da pesquisa são as normas que foram criadas no sistema internacional para harmonizar os fluxos econômicos globais e possibilitar a prestação de informações mais claras nas demonstrações financeiras. Trata-se de estudo exploratório e bibliográfico. A temática tem como objetivo geral analisar as relações de globalização e o processo que tange a harmonização contábil no meio internacional e objetivos específicos buscou demonstrar o entendimento das normas contábeis internacionais, a convergência aos padrões internacionais no mundo, a análise dos aspectos da economia global contemporânea e dos fluxos econômicos globais. As informações levantadas confirmaram a influência favorável a padronização dos procedimentos contábeis sobre a harmonização dos fluxos econômicos globais, principalmente por possibilitar aos usuários da informação contábil, a compreensão dos relatórios elaborados em diferentes países.

Palavras-Chave: Normas de Contabilidade, Convergência Internacional, Fluxos Econômicos Globais.

\section{INTRODUÇÃO}

Nagatsuka e Teles (2002) lecionam que o desenvolvimento da Contabilidade durante toda sua história esteve fortemente ligado ao desenvolvimento econômico e às transformações sociopolíticas e 
socioculturais experimentadas em cada época. Dessa forma, em um mundo globalizado, as políticas internacionais se intensificaram, o sistema comercial acelerou, a humanidade evoluiu e a contabilidade também, sendo necessária a criação de um sistema convergente de normas internacionais de contabilidade, para prestar informações de forma clara e eficaz às partes interessadas aos diversos grupos de usuários.

Silva e Madeira (2004) comentam sobre a grande influência do meio em que a contabilidade está inserida, mencionando como uma linguagem da informação que não é homogênea, sendo assim, mudando de acordo com cada país. Anteriormente, havia diferentes práticas contábeis nos diversos países, o que dificultava muito as informações contidas nas demonstrações financeiras. A convergência contábil atrelouse a um trabalho em conjunto dos países (multilateralismo econômico), que desencadeou impactos positivos na atual conjuntura global.

De acordo com Bueno e Lopes (2005), o processo de globalização dos mercados, com o avanço de capital internacional, impulsionou o crescimento dos investimentos diretos estrangeiros e à formação de blocos econômicos. Portanto, os diferentes critérios e práticas adotados por cada país não facilitavam uma compreensão e a realização de transações comerciais, o que acarretava vários prejuízos econômicos às partes interessadas. Assim, trouxe consigo a necessidade de se formular um conjunto de normas contábeis internacionais que se responsabilizassem por viabilizar um comparativo de informações entre companhias de um mesmo grupo ou de grupos distintos.

Com a intenção de resolver para atender às demandas da globalização (processo que se iniciou após a segunda guerra mundial), houve um esforço global entre as potências econômicas como Estados Unidos e União Europeia, por uma criação de Comitês Internacionais de Contabilidade, que se tornaram responsáveis por buscar soluções de convergências contábeis, colocando um ponto em comum nos relatórios financeiros elaborados por contextos de outros países e definindo métodos de adaptação aos padrões internacionais a partir da contabilidade local. Desse modo, publicou-se de forma totalmente independente um novo padrão de normas contábeis internacionais, na qual, facilitaria a compreensão dos demonstrativos, a comparabilidade e a clareza que os envolve ( FLOWER, 2002).

Para Lucena, Leite e Nyama (2011), a busca por esclarecimento sobre os aspectos econômicos da convergência contábil constituem características positivas nas prestações de informações dos sistemas patrimoniais. Os desenvolvimentos de alianças estratégicas com certos modelos econômicos comprometidos com a gestão econômica de mercado se caracterizam como elementos básicos para uma gestão eficaz. Além disso, a existência de uma credibilidade em relação às normas de contabilidade é essencial para que haja uma harmonização e para que seja atingido um grau de confiabilidade, desenvolvendo assim uma maior transparência e segurança às informações contábeis.

Lucena, Leite e Nyama (2011) afirmam ainda que, em um mundo globalizado, uma das mais importantes vantagens da harmonização contábil entre países, sem dúvidas, é o fluxo econômico que se fundamentaliza na utilização de métodos de reavaliação e estratégias econômicas entre empresas e o mercado internacional. Portanto, é evidente a importância das normas internacionais de contabilidade para o progresso uniforme e para o estreitamento cada vez maior das convergências contábeis entre nações.

Para Zurne (2013), colocou em debate o processo de interdependência que se desenvolveu principalmente 
ao longo da década de 1970 e a literatura sobre globalização floresceu durante a década de 1990, possuindo alguns aspectos em comum no que concernem as relações internacionais. A importância da abordagem é clara devido a necessidade do entendimento como um todo do passo a passo em que a contabilidade internacional vem ganhando espaço no sistema econômico mundial.

Neste contexto, o objetivo deste presente estudo é investigar como as normas internacionais de contabilidade podem influenciar na harmonização dos fluxos econômicos globais. Desta forma, expõe-se um tema atual e de grande relevância para os profissionais e acadêmicos da área contábil que visam à adaptação diante das novas responsabilidades trazidas pelas normais internacionais de contabilidade, além das contribuições positivas que foram alcançadas no processo de globalização e as perspectivas futuras para o avanço da contabilidade.

\section{METODOLOGIA}

Trata-se de pesquisa exploratória e bibliográfica desenvolvida por meio de análises em livros, artigos, monografias, dissertações de mestrado e teses de doutorados, visando coletar o conteúdo necessário para o estudo em questão por meio da seleção e interpretação das contribuições teóricas já existentes sobre o assunto.

A pesquisa exploratória, conforme Amboni (1997) possui como principal finalidade o desenvolvimento e o esclarecimento de conceitos e ideias, para a formulação de abordagens mais condizentes com o desenvolvimento de estudos posteriores. Por esta razão, a presente pesquisa exploratória constituiu uma etapa de um estudo importante e minucioso, no qual busca familiarizar o pesquisador com o assunto investigado.

Já a pesquisa bibliográfica promove a verificação dos dados obtidos através do acervo pesquisado, confrontando informações entre as diversas literaturas publicadas sobre o tema. A esse respeito, Marconi e Lakatos(1990) lecionam que a pesquisa bibliográfica se deu por meio da coleta de material ou de fontes secundarias, abrangendo toda bibliografia já tornada publica em relação ao tema de estudo, desde publicações avulsas até meios de comunicações orais.

\section{REFERENCIAL TEÓRICO}

\section{NORMAS INTERNACIONAIS DE CONTABILIDADE E SUAS ESPECIFICAÇÕES}

A Contabilidade entrelaçada com uma diversidade de novos desafios ocasionados pelas constantes mudanças no cenário econômico mundial, na qual o processo de economia globalizada, os avanços dos mercados de capitais internacionais e o aumento dos investimentos estrangeiros ocasionam a necessidade de utilização de normas e procedimentos que contribuam para a diminuição das diferenças nas informações contábeis entre os países (BARBOSA NETO; DIAS; PINHEIRO, 2009).

Diversos organismos internacionais foram envolvidos no processo que buscou a harmonização da Contabilidade entre os países (NIYAMA, 2007).

De acordo com Niyama e Rodrigues (2010) mencionam sobre o surgimento das normas internacionais na contabilidade, evidenciam a finalidade da harmonização mediante aos padrões contábeis, além de colocar 
em pauta as disparidades apresentadas nas demonstrações financeiras. Então, foi necessária a criação de comitês internacionais, que foram responsáveis por fazer jus às necessidades internacionais na "corrida econômica". A contabilidade é substancial para o auxilio a administração para a tomada de decisões. . Sendo a mesma responsável pela coleta de dados, mensurando-os monetariamente, registrando-os e buscando catalogar em forma de relatórios.

Portanto, a existência de organismos comprometidos com as formulações de normas internacionais que fossem aceitas mundialmente foi essencial para estreitar as relações entre os países a partir de 1973. Nesse sentido, com o intuito de buscar soluções homogêneas, órgãos internacionais vêm mostrando a importância de harmonizar as práticas contábeis, a nível mundial, evidenciando, então, a contabilidade como a língua universal dos negócios (Oliveira; Oliveira, 2008). O International Accounting Standards Committee - IASC nasceu no ano de 1973 com a ajuda de contadores de vários países, como: Alemanha, Austrália, Canadá, Estados Unidos da América, França, Irlanda, Japão, México, Países baixos e Reino Unido (IFRS, 2014).

Barbosa Neto, Dias e Pinheiro (2009) ressaltaram o esforço do International Accounting Board (IASB), do International Federation of Accounting (IFAC), do International Organizational of Securities Commission (IOSCO), das Nações Unidas, da União Européia e do Financial Accounting Standards Board (FASB) no desenvolvimento de ações voltadas para a normatização contábil internacional. Esses órgãos são encarregados, entre outras atribuições, da emissão de pronunciamentos, interpretações, opiniões, boletins técnicos, relatórios e conceitos sobre a aplicação de normas contábeis em nível internacional. Contudo, têm a missão de buscar mais transparência nas informações contábeis, de forma a reduzir custos dos demonstrativos financeiros das empresas, a centralização e a uniformização da produção de procedimentos contábeis.

O IASB (International Accounting Standard Board), sucessor do IASC (International Accounting Standards Committee), é o órgão de grande importância na busca de harmonização, sendo a promoção da convergência das normas contábeis a nível internacional uma de suas funções. Formado por vários países, o IASB é um organismo independente que tem como competência o desenvolvimento de normas que sejam compreensíveis, para o fornecimento de informações que vão de encontro aos padrões da contabilidade (LEMES; SILVA, 2007).

Baseado na constituição do IASB, Niyama e Silva (2008) apresentam como sendo os objetivos desse organismo: o desenvolvimento de um conjunto uniforme de normas contábeis utilizadas na elaboração e apresentação das demonstrações contábeis, a nível mundial, utilizando informações de alta qualidade, comparáveis e transparentes, que auxiliem na tomada de decisões econômicas; a promoção e aplicação de forma rígida dessas normas; e, a promoção da convergência das normas contábeis ao padrão internacional.

As normas internacionais de contabilidade recebiam o nome de IAS (International Accounting Standards) e, atualmente, são conhecidas como IFRS (Internacional Financial Reporting Standards). Emitidas pelo $I A S B$, essas normas são pronunciamentos baseados em princípios e não em regras específicas (IFRS, 2008).

Quando se fala do IFRS, Madeira (2004) reforça que esses padrões emitidos pelo IASB, foram considerados uma revolução no mercado financeiro a partir de 2005. Seguindo o mesmo sentido da obra, 
para Carvalho, Lemes e Costa (2006, p. 19), "os IFRS ganharam uma proporção enorme quanto a sua importância, com a sua obrigatoriedade em empresas que estão na bolsa da União Europeia a partir de 2005". Portanto, de acordo com autores acima mencionados, são oportunas as pesquisas sobre contabilidade internacional, pois o IFRS é um tema atual e de relevância para os usuários da informação contábil. Para uma busca de maior teor de veracidade as normas buscam internacionalizar informações contábeis pertinentes para melhores demonstrações de instituições no âmbito nacional em relação suas matrizes e filiais no exterior (MADEIRA, 2004).

O ideal das classes contábeis é alcançar maior confiabilidade e transparência diante dos usuários, desenvolvendo informações seguras, o que explica a harmonização das normas de Contabilidade terem se tornado de grande interesse (MARION; IUDÍCIBUS, 2006).

Dessa forma, para atender às necessidades da classe contábil, os comitês internacionais se constituem como instrumento indispensável. Assim, a regulação das normais contábeis é fundamental tanto para a harmonização, quanto para a manutenção das relações econômicas harmônicas.

\section{HARMONIZAÇÃO CONTÁBIL E NOVOS CONCEITOS}

A contabilidade tem como finalidade disponibilizar a seus usuários as informações contábeis necessárias para a avaliação econômica e financeira da entidade. Iudícibus (2010) afirma que um dos objetivos da contabilidade é avaliar períodos passados e futuros para fornecimento de informações pertinentes a tomada de informações gerenciais.

Segundo Missagia e Velter (2005), o fornecimento de informações contábeis é indispensável para o bom andamento da "sobrevivência financeira" de qualquer entidade. Dessa forma, se faz necessário à evidenciação das mesmas, tanto no Brasil, quanto no campo internacional.

Portanto, a harmonização das normas contábeis é uma busca constante nas reuniões das entidades internacionais que lidam com normas contábeis, onde se procura refletir sobre as vantagens e desvantagens, a pressão exercida pelos usuários da contabilidade, a influência da crescente globalização da economia e os obstáculos à adoção da harmonização.

De acordo com orientações de Niyama e Silva (2008) a contabilidade internacional tem como intenção levar aos profissionais da área os conhecimentos sobre as normas internacionais de contabilidade vigentes no mundo, buscando uma maneira de adaptar as demonstrações contábeis de acordo com as exigências de certos países, buscando padrões uniformes, transparentes e comparáveis. Assim, torna-se mais acessível atender os interesses das expansões comerciais e financeiros das empresas no âmbito internacional. Portanto, os profissionais devem estar cada vez mais envolvidos nos na necessidade de investimentos e avanços tecnológicos que permitem fácil acesso a informação, assim, torna-se fundamental para melhor estabelecer as responsabilidades comerciais e financeiras no sistema globalizado. Diante disso, as demonstrações financeiras serão estabelecidas com maior confiabilidade, atendendo melhor os interesses de classes.

A harmonização é um processo pelo qual demasiados países, de comum acordo, realizam mudanças nos seus sistemas e normas contábeis, tornando-os compatíveis, respeitando características de cada região. Esse processo considera a influência dessas normas na economia dentro de um contexto de unicidade de 
mercados (MADEIRA; ALMEIDA; FABIANA, 2004). É crescente a importância das normas internacionais para alcançar a harmonização contábil e, no processo de avaliar o conteúdo delas, percebese que a mesmas fornecem algum progresso à uniformidade, pois à formação de cada norma, uma quantidade de uniformidade é adicionada rumo à harmonização Esse processo se torna mais viável e busca atender às necessidades das partes interessadas da maneira mais clara possível, mantendo harmônicas as relações nesse fluxo de mercado global (MADEIRA; ALMDEIDA; FABIANA, 2004).

Para Rosa (1999) a crescente internacionalização da economia, fez o surgimento de blocos econômicos continentais e regionais, que somam esforços conjuntos para ampliação de suas reações socioculturais, fazendo que, recentemente, se busque, por meio da cooperação, o desenvolvimento socioeconômico entre os países e, dessa forma, fortalecendo a competitividade global.

O acelerado processo do desenvolvimento global fez com que os países criassem maneiras de facilitar as relações entre elas, seja comercial ou não. As nações criaram meios cada vez mais simplificados de união, para deixar "práticos" os acordos bilaterais. De acordo com Rosa (1999) a formação de blocos econômicos, como a União Europeia, o Nafta, o Mercosul, constitui um fator fundamental para a harmonização das práticas contábeis. A partir do momento que as empresas pertencentes aos países integrantes desses blocos, passam a adotar as suas práticas de acordo com o contexto transnacional, fazendo com que as suas operações obedeçam a um sistema de registro contábil e de informações integrado e convergente.

A formulação desses blocos é o que destaca claramente esse processo de trabalho em conjunto dos países para que possa desencadear a busca por troca de informações entre diferentes mercados globais. Cada vez mais, as corporações evoluem e os países buscam estreitar as relações para o bom andamento desses mercados globais. A harmonização das normas contábeis deve ser percebida como um processo natural resultante do amadurecimento das relações sociais e comerciais, devendo ser realizada sem imposição e de forma a não contrariar a Contabilidade enquanto ciência (MEIRELLES JUNIOR; MEIRELLES, 2009).

A ideia central de harmonizar os acordos bilaterais entre as nações foi fundamental para $o$ estabelecimento de normas internacionais. Dessa forma, os países cada vez mais têm interesses de desenvolver maneiras de melhorar as trocas de informações, buscando uniformizar as relações (NYIAMA,2005).A ausência de uniformidade das normas e procedimentos contábeis compromete a comparabilidade das informações apresentadas através das demonstrações financeiras (AVELINO et al., 2010).

Esse processo de harmonização das normas contábeis ao padrão internacional, contudo, dever ser realizado com cautela, tendo em vista alcançar o objetivo de comparabilidade das informações contábeis, além de manter os próprios princípios fundamentais da Teoria Contábil (LUCENA; LEITE; NIYAMA, 2011).

As instituições políticas (inclusive o Estado) têm como objetivo propagar a competitividade de suas economias, pois é a concorrência nos mercados globais que determina a percentagem de riqueza (CASTELLS, 1999). Nesse contexto, as instituições internacionais passaram a ter maior poder políticoeconômico tão quanto ou maiores que os próprios Estados. 
O entendimento sobre as extensões da internacionalidade da Contabilidade é essencial para todos que desejem negociar por fronteiras nacionais e internacionais, no qual as buscas por capitação de investimentos estrangeiros demandam a utilização de normas e procedimentos contábeis. Então, esse fato reforça a ideia de buscar pela harmonização de normas contábeis, para que dessa forma as demonstrações financeiras sejam adequadamente avaliadas também no exterior (BARBOSA; DIAS; PINHEIRO, 2009).

Portanto, observando a real importância de tais fatos mencionados, evidencia-se que o processo de criação de um cenário oportuno para o estudo das direções das pesquisas na harmonização contábil internacional e para as investigações de como as pesquisas procederão a partir desses acontecimentos (BAKER; BARBU, 2007). Então, estes fatores promovem a ampliação do objetivo geral da contabilidade internacional, promovendo informações aos usuários internos e externos da entidade, em função do processo de globalização.

\section{FLUXOS ECONÔMICOS GLOBAIS}

Os fluxos econômicos na era globalizada apresentam-se por meio de transações monetárias, empresas, bens e serviços. Contudo, frente aos grandes avanços proporcionados no âmbito nos mais diversos meios, a economia mundializou-se e passou a integrar todas as diferentes partes do mundo, embora de maneira desigual e hierárquica (PENA, 2017). De acordo com Castells (2000), uma economia com capacidade de funcionar como uma unidade em tempo real, em escala planetária, considera-se global. A criação de novos níveis de conectividade entre os países desempenha um papel maior entre as nações, empresas e pessoas. Dessa forma, as redes de fluxos econômicos globais se expandem de maneira rápida e sistemática, buscando sempre ir além dos limites, sejam eles temporários ou geográficos. Para Porter (1986), há diversos atributos estratégicos para fomentar a competição global e definir os vencedores e os perdedores, como a diminuição das barreiras alfandegárias, a desregulamentação financeira, a governança global, entre outros, observando, claro, os pontos fortes e fracos críticos.

Portanto, o modelo de Porter (1986) sustenta a ideia de que as forças que atuam no sentido de aumentar a concorrência em um determinado setor, interferem no retorno sobre o capital investido, ampliando a circulação e gerando a diminuição dos custos de produção e de serviços, além de ampliar a demanda destes.

Em suma, os fluxos econômicos consistem em mostrar as transações, compras e vendas, como de fato elas são não importando se entrou dinheiro no caixa efetivamente em decorrência delas ou não. Portanto, este fluxo é uma forma de analisar o comportamento das empresas que estão cada vez mais envolvidas na circulação de capitais, na qual é altamente relevante para o progresso da economia global.

\section{A INFLUÊNCIA DAS NORMAS INTERNACIONAIS NOS FLUXOS ECONÔMICOS GLOBAIS}

No que se relaciona à contabilidade internacional, a partir da globalização dos mercados, deixa-se claro a importância dos investidores compreenderem a linguagem contábil de cada país. Dentre os tópicos mais pesquisados sobre contabilidade internacional, destacam-se a existência de diferentes modelos contábeis no mundo e o processo de harmonização contábil internacional (FARIAS; FARIAS, 2009).

Fica claro que toda essa ideia de harmonização é responsável por trazer vantagens no que se relaciona as organizações mundiais e para o comércio internacional, principalmente para os países emergentes, como 
o Brasil, que busca expansão de suas fronteiras para investimentos estrangeiros. Além disso, outras vantagens se relacionam as reduções de custos para o gerenciamento de sistemas contábeis nos mais diversos países e a realização de auditoria nos "quatro cantos" do mundo com a mesma linguagem contábil (NYIAMA, 2005).

Movimentos voltados a favor da internacionalização das normas contábeis já envolve, hoje em dia, mais de 100 países, que já exigem ou permitem que suas empresas adotem as normas contábeis do International Financial Reporting Standards - IFRS. Dessa maneira, esse procedimento de adequação não é tão simples, levando em consideração as diferenças de ordem política, cultural e de legislação (REZAEE; SMITH; SZENDI, 2010).

A existência de práticas contábeis, das mais variadas formas entre países, e a intrínseca necessidade de preparação de demonstrações financeiras, nos mais diversos padrões internacionais pelas empresas multinacionais, geraram dificuldades de interpretação das informações, o que ocasionou a busca por maneiras voltadas ao alcance de uma simplificação desse sistema, tornando a globalização do mercado de capitais e a internacionalização das empresas dois dos fatores mais importantes para se entender o processo de busca da harmonização das normas internacionais de contabilidade (FARIAS; FARIAS, 2009).

O mesmo autor ainda comenta sobre as diversas formas das prestações de informações nas práticas contábeis, dificultaria o processo informacional de contabilidade, diminuindo a confiança dos investidores, ao utilizá-las como insumo para suas decisões. Dessa forma, tornou-se essencial a busca pela harmonização das práticas contábeis, para satisfazer as necessidades dos investidores estrangeiros quando procuram oportunidades de negócios.

A grande necessidade das empresas gerarem demonstrativos financeiros e as diferentes formas de atender às exigências no processo globalizado geraram problemas nas gerências das multinacionais. Tais problemas, como a Consistência: Quando se torna possível que os relatórios financeiros possam ocasionar informações distintas (por exemplo, que à matriz indica uma perda e, que de acordo com a lei local, um lucro) gerando incerteza aos usuários, ocasionando confusões ao medir o desempenho da subsidiária estrangeira. Nesse caso, a gerência do grupo pode exigir que o desempenho seja medido de acordo com seus princípios padrões. E o Custo: Não é barato manter um sistema de contabilidade que organize duas demonstrações financeiras distintas (FLOWER, 2002).

Contudo, destacam-se os benefícios esperados com a harmonização contábil, os quais são: eliminação das práticas contábeis enganosas; limitação das habilidades dos gestores em distorcer os dados; redução dos custos relativos à preparação e interpretação das demonstrações financeiras; melhores condições na seleção de alternativas de investimentos e o treinamento e a educação (FALK, 1994).

Assim, observa-se que objeto da harmonização internacional é a mensuração e a divulgação, com a intenção de deixar claras as comparações entre as demonstrações financeiras na prestação de informações. Dessa forma, se faz necessário a definição de um padrão internacional de contabilidade, buscando a redução no número de escolhas contábeis possíveis, para tornar prática a avaliação das transações econômicas.

Para Carvalho, Lemes e Costa (2006), a contabilidade internacional surgiu para minimizar as aflições de 
quem queria fazer investimentos fora do país e até hoje tinha que manusear balanços em dezenas de normas contábeis distintas, tentando compatibilizá-las para comparar. Então, pode-se constatar que esse é o papel da contabilidade internacional, evidenciando a influência das normas internacionais na harmonização dos fluxos econômicos globais.

\section{ESTUDOS EMPÍRICOS ANTERIORES}

Com o intuito de observar alguns resultados empíricos da convergência contabilística no cenário mundial, o Quadro 1 apresenta artigos empíricos levantados para o período de 2000 a 2017.

Quadro 1 - Estudos empíricos no cenário mundial

\begin{tabular}{|c|c|c|c|}
\hline Autor (ano) & Objetivo & País(es) & Metodologia \\
\hline $\begin{array}{l}\text { Dela Ricci; Nakao e } \\
\text { Zuliani (2004). }\end{array}$ & $\begin{array}{c}\text { Objetiva buscar } \\
\text { informações se há } \\
\text { diferenças contábeis ao } \\
\text { comparar duas normas } \\
\text { em uma mesma empresa. }\end{array}$ & Brasil & $\begin{array}{c}\text { Foi necessária a } \\
\text { utilização de uma } \\
\text { amostra de dados obtida } \\
\text { junto aos balanços } \\
\text { patrimoniais de } 2001 \text { e } \\
2002 \text { das empresas } \\
\text { brasileiras listadas na } \\
\text { New York Stock } \\
\text { Exchange (NYSE). }\end{array}$ \\
\hline $\begin{array}{l}\text { Mirza; Holt e Orrell } \\
\qquad(2006)\end{array}$ & $\begin{array}{l}\text { Mostrar a necessidade do } \\
\text { surgimento urgente de } \\
\text { promulgação de um } \\
\text { conjunto comum de } \\
\text { padrões contábeis } \\
\text { globais ou, em outras } \\
\text { palavras, convergência } \\
\text { global para uma } \\
\text { linguagem comum de } \\
\text { contabilidade para o } \\
\text { mundo financeiro. }\end{array}$ & Estados Unidos & $\begin{array}{c}\text { Qualitativa e } \\
\text { quantitativa. Fornece } \\
\text { estudo de casos( com } \\
\text { trabalhos soluções), } \\
\text { perguntas de múltiplas } \\
\text { escolhas ( com } \\
\text { respostas) e informações } \\
\text { praticas. }\end{array}$ \\
\hline Malaquias (2008) & $\begin{array}{c}\text { Apontar de forma } \\
\text { quantitativa a distância } \\
\text { do nível de disclosure } \\
\text { das demonstrações }\end{array}$ & Brasil & $\begin{array}{l}\text { Analise de relatórios } \\
\text { contábeis anuais que tais } \\
\text { empresas forneceram a } \\
\text { dois diferentes mercados }\end{array}$ \\
\hline
\end{tabular}




\begin{tabular}{|c|c|c|c|}
\hline & $\begin{array}{l}\text { financeiras de empresas } \\
\text { brasileiras em relação às } \\
\text { exigências dispostas pelo } \\
\text { IASB (International } \\
\text { Accounting Standards } \\
\text { Board), para a } \\
\text { evidenciação de } \\
\text { instrumentos financeiros. }\end{array}$ & & $\begin{array}{c}\text { de capitais: o brasileiro, } \\
\text { com as DFP } \\
\text { (Demonstrações } \\
\text { Financeiras } \\
\text { Padronizadas), e o norte- } \\
\text { americano, com os } \\
\text { Form_20F. }\end{array}$ \\
\hline Alves e Antunes (2010). & $\begin{array}{c}\text { Consiste em estudar o } \\
\text { processo de } \\
\text { harmonização } \\
\text { contabilística na União } \\
\text { Europeia. Os resultados } \\
\text { deste estudo permitem } \\
\text { concluir pela } \\
\text { importância vital da } \\
\text { harmonização } \\
\text { contabilística para o } \\
\text { desenvolvimento da } \\
\text { economia global. }\end{array}$ & Portugal & $\begin{array}{l}\text { Revisões de literaturas e } \\
\text { analises comparativas. }\end{array}$ \\
\hline Oliveira e Lemes (2011). & $\begin{array}{l}\text { Fazer uma avaliação } \\
\text { acerca de que nível as } \\
\text { informações contábeis } \\
\text { divulgadas nos } \\
\text { mercados: brasileiro e } \\
\text { norte-americano } \\
\text { atendem aos requisitos } \\
\text { da adoção inicial das } \\
\text { IFRS - International } \\
\text { Financial Reporting } \\
\text { Standards. }\end{array}$ & Brasil & $\begin{array}{c}\text { Pesquisa descritiva } \\
\text { quanto aos seus } \\
\text { objetivos e utilizando-se } \\
\text { dos procedimentos } \\
\text { técnicos de pesquisa } \\
\text { documental e de análise } \\
\text { de conteúdo clássica. }\end{array}$ \\
\hline $\begin{array}{c}\text { Freire; Machado; } \\
\text { Machado e Souza (2012) }\end{array}$ & $\begin{array}{l}\text { Analisar o processo de } \\
\text { convergência às normas } \\
\text { internacionais de }\end{array}$ & Brasil & $\begin{array}{c}\text { Realização de um estudo } \\
\text { empírico sobre as } \\
\text { empresas brasileiras }\end{array}$ \\
\hline
\end{tabular}




\begin{tabular}{|c|c|c|c|}
\hline & $\begin{array}{c}\text { contabilidade na qual } \\
\text { teve início com as } \\
\text { alterações da lei das } \\
\text { Sociedades Anônimas } \\
\text { (6.404/76), promovidas } \\
\text { pelas leis 11.638/07 e } \\
11.941 / 09 .\end{array}$ & & $\begin{array}{c}\text { listadas na BM\&F } \\
\text { Bovespa foi realizada. }\end{array}$ \\
\hline $\begin{array}{l}\text { Teodoro; Teodoro; } \\
\text { Macedo; Costa e } \\
\text { Tosta(2013). }\end{array}$ & $\begin{array}{c}\text { Objetivo analisar e } \\
\text { evidenciar diante da } \\
\text { percepção dos discentes } \\
\text { do curso de ciências } \\
\text { contábeis, de que } \\
\text { maneira o processo de } \\
\text { convergência contábil } \\
\text { tem impactado a tríade } \\
\text { indissolúvel do ensino, a } \\
\text { pesquisa e a extensão. }\end{array}$ & Brasil & $\begin{array}{c}\text { Levantamento } \\
\text { bibliográfico, uma } \\
\text { pesquisa de campo com } \\
\text { utilização de um } \\
\text { questionário com } \\
\text { perguntas abertas. }\end{array}$ \\
\hline $\begin{array}{l}\text { Pinheiro; Azevedo e } \\
\text { Cruz (2013). }\end{array}$ & $\begin{array}{l}\text { Descrever a evolução do } \\
\text { normativo contabilístico } \\
\text { português e apresentar as } \\
\text { diferenças estruturais } \\
\text { entre o atual modelo } \\
\text { contabilístico (SNC) e o } \\
\text { modelo antecessor } \\
\text { (POC). }\end{array}$ & Portugal & $\begin{array}{l}\text { Metodologia qualitativa, } \\
\text { assente na análise } \\
\text { documental sobre a } \\
\text { matéria em estudo e de } \\
\text { diplomas contabilísticos. }\end{array}$ \\
\hline
\end{tabular}

Fonte: elaborado pelo autor.

Conforme as análises dos autores supracitados ficaram-se claro o desenvolver em suas obras os estudos empíricos em observância das respostas das normas internacionais de contabilidade em olhar global. Desta forma a linguagem universal dos negócios é otimizada por ser o canal de comunicação dos mais diversos usuários em suas atividades.

Dela Ricci; Nakao e Zuliani (2004) buscou desenvolver nesse trabalho o fato de evidenciar aos tomadores de decisão se há informações contábeis diferentes ao comparar duas normas de uma mesma empresa, tendo em vista também as particularidades quanto à tradução de balanços. Contudo, destacou a avaliação do índice de liquidez corrente, cuja finalidade é a de verificar a capacidade de pagamento da entidade em 
curto prazo, considerando itens ativos e passivos circulantes.

Rodrigues; Pereira (2004) se baseia na harmonização das normas de contabilidade, na qual só será bemsucedida se essas normas proporcionarem informação credível estável num relato financeiro transparente. Assim, qualquer associação de normas de contabilidade, que pretenda uma aceitação global, deverá ser estruturada, tendo em conta as necessidades dos investidores e dos mercados de capitais.

Mirza; Holt e Orrell (2006) em sua obra retratam um momento desafiador para a contabilidade internacional. Os grandes avanços na era globalizada fez-se necessário a promulgação de um conjunto comum de padrões contábeis.

Malaquias (2008) retrata a importância dos relatórios fornecidos aos mercados de capitais brasileiros, o índice de evidenciação para a disclosure de instrumentos financeiros. Assim, evidencia-se o quão próximo estão os relatórios contábeis das empresas brasileiras do exigido pelas normas internacionais em sua evidenciação de instrumento financeiro.

Alves e Antunes (2010) enfatizaram uma evidenciação da harmonização contabilística internacional com grande relevância devido ao processo de globalização. Nesse processo, destacou-se a União EuropeiaUE, como uma grande propulsora dessa normatização/harmonização internacional no sentido de remover todas as barreiras alfandegarias.

Oliveira e Lemes (2011) colocam em pauta o sistema de integração dos mercados de capitais, possibilitando que investidores sejam capazes de empregar recursos financeiros em qualquer lugar do globo. A obra deste autor promove um estudo sobre as normas internacionais de contabilidade no contexto de empresas brasileiras e promovem reflexões sobre a relevância do tema em questão.

Freire; Machado; Machado e Souza (2012) evidência em sua obra a contabilidade como a linguagem universal dos negócios, e por conta disso, vem buscando por uma convergência de suas normas por vários países. Diante isso, os autores buscaram identificar empresas brasileiras do setor de bens industriais, para envolver em um processo de convergência para as normas internacionais de contabilidade.

Teodoro; Teodoro; Macedo; Costa e Tosta (2013) retrataram as recentes mudanças aplicadas a ciência contábil, sobretudo relacionada a convergência contábil das normas internacionais. Assim, o objetivo do estudo é esclarecer o processo de convergência contábil e seus impactos no sistema de ensino, pesquisa e extensão. Finalizando, Pinheiro; Azevedo e Cruz (2013) colocam em pauta a evolução dos negócios, evidenciando a contabilidade em grandes desafios enquanto sistema da informação. Assim, deixam clara a importância da normatização das normas no processo de globalização, por tem sido fundamental para caracterizar o atual sistema de mercado, na busca de romper as barreiras de comercio mundial e assim, aumentar as operações financeiras.

\section{CONCLUSÃO}

No presente trabalho verificou-se que a Contabilidade em sua contínua dinamicidade sempre busca se adaptar às novas realidades. Dessa forma, também permitiu por meio de pesquisas bibliográficas uma análise das percepções acerca da contabilidade internacional no que concerne ao sistema globalizado e seus fluxos econômicos, evidenciando a importância da temática em questão. 
O desenvolvimento do presente estudo possibilitou uma análise da importância das Normas Internacionais de Contabilidade. Os resultados encontrados no trabalho evidenciaram os alcances dos objetivos propostos e ainda a possibilidade de elaborar novos trabalhos, avançando assim os estudos sobre a temática.

Ao longo destas páginas foram apresentados um panorama sobre a busca da Harmonização Contábil no que concerne ao processo de globalização, o que acabou culminando nos avanços da Contabilidade Internacional. Em razão dessas mudanças impactantes, tanto os seus operadores como os próprios usuários tiveram que passar por uma fase de adaptação, a fim de que pudessem melhor utilizar esses instrumentos e se familiarizar a este novo procedimento.

A realização deste trabalho proporcionou a obtenção de maiores conhecimentos sobre a temática em questão. Então, fica evidente que a influência das normas internacionais de contabilidade possibilitou uma busca por harmonização dos fluxos econômicos globais. Portanto, torna-se necessário os conhecimentos da contabilidade internacional no atual sistema de mercado na era globalizada, além de identificar autores com grande potencial que apresentam um conhecimento valorativo à temática, dando uma contribuição significativa do conhecimento abordado.

No entanto, por se tratar de um assunto contemporâneo e de grande valor para a contabilidade, ainda haverá muito que se discutir. Dessa maneira, a ideia será buscar oportunizar novos estudos, bem como abranger uma área maior para realização da pesquisa, que será responsável por aprofundar a temática sobre as Normas Internacionais de Contabilidade e a busca por harmonização nos fluxos econômicos globais.

\section{REFERÊNCIAS}

ALVES, M. C. G.; ANTUNES, E. C. (2010). A implementação das Normas Internacionais de Contabilidade na Europa: um estudo comparativo. Texto para discussão \#10. Universidade da Beira Interior, Departamento de Gestão e Economia. Disponível em: <http://www.dge. ubi.pt/investigacao/TDiscussao/TD10_2010.pdf>. Acesso em: XX mmm. Ano.

AMBONI, Nério. O Caso da cecrisa s.a.: uma aprendizagem que deu certo. Tese de Doutorado, EPS UFSC - Florianópolis: 1997.

ARAÚJO, A. M. P. de; ASSAF NETO, A. A Contabilidade Tradicional e a Contabilidade Baseada em valor. Revista Contabilidade \& Finanças, São Paulo, n. 33, p. 16-32, set./dez. 2003. AVELINO, B. C. et al. Análise do perfil dos estudantes em Ciências Contábeis e sua relação com o processo de convergência das normas contábeis. Revista Brasileira de Contabilidade, Brasília, n. 182, p. 63-77, mar./abr. 2010.

BARBOSA NETO, J. E. ; DIAS, W. de O.; PINHEIRO, L. E. T.a. Impacto da Convergência para as IFRS na Análise Financeira: um estudo em empresas brasileiras de capital aberto. Contabilidade Vista \& Revista, Belo Horizonte, v. 20, n. 4, p. 131-153, out./dez. 2009.

BAKER, C. R.; BARBU, E. M.. Trends in research on international accounting harmonization. The International Journal of Accounting, V. 42, n. 3, p. 272-304. 2007.BUENO, Artur Franco; LOPES, 
Edmir. Harmonização Global das Práticas Contábeis. Contabilidade Internacional, São Paulo, módulo 2, 2005a.

CALIXTO, L. Análise das pesquisas com foco nos impactos da adoção do IFRS nos países europeus. Contabilidade Vista \& Revista, Belo Horizonte, v. 21, n. 1, p. 157-187, jan./mar. 2010.

CANDIDO, W. Mundialização do Capitalismo. Disponível em: <https://washingtoncandido.wordpress.com/2011/02/25/mundializacao-do-capitalismo/ >. Publicado em: XX fev./2011. Acesso em: XX mmm. Ano.

CARVALHO, L. N; LEMES, S.; COSTA, F. M.. Contabilidade internacional: aplicação da IFRS 2005. São Paulo: Atlas, 2006.

CASTELlS, M. A rede e o ser. São Paulo: Paz e Terra, 1999.

CASTELLS, M. A sociedade em rede: a era da informação: economia, sociedade e cultura. I. São Paulo: Paz e Terra, 2000. 698 p.

COSTA, C. L.; CAMPOS, F. M. de; AMARAL, M. M. Capacitação Profissional: um estudo sobre a adoção das normas internacionais de contabilidade (IFRS) nas instituições particulares de ensino superior do ABC. Revista Brasileira de Contabilidade, Brasília, n. 177, p. 77-89, maio/junho 2009.

DELA RICCI, M. A.; NAKAO, S. H.; ZULIANI, I.. Análise do índice de liquidez corrente diante da adoção de diferentes normas contábeis. In: CONGRESSO USP DE CONTROLADORIA E CONTABILIDADE, São Paulo, 2004. .. São Paulo: USP, 2004.

FALK H.. International accounting: a quest for research. Contemporary Accounting Research. v. 11, n. 1. p. 595-615. Fall 1994.

FARIAS, M. R. S.; FARIAS, K. T. R. Tópicos para pesquisa sobre contabilidade internacional: evidências empíricas no Brasil. In: ENCONTRO DE ENSINO E PESQUISA EM ADMINISTRAÇÃO E CONTABILIDADE, Curitiba, 2009. Anais... São Paulo: ANPAD, 2009.

FERREIRA, A. B. de H. Novo dicionário da língua portuguesa. Rio de Janeiro: Nova Fronteira, 2002.

FLOWER, J. Global Financial Reporting. New York: Palgrave, 2002.

FREIRE, M. D. M.; MACHADO, M. R. R.; MACHADO, L. S.; SOUZA, E. S.; OLIVEIRA, J. J. Aderência às normas internacionais de contabilidade pelas empresas brasileiras. Revista de Contabilidade e Organizações, v. 6, n. 15, p. 3-22, 2012.INSTITUTO AMERICANO DE CONTADORES PÚBLICOS CERTIFICADOS, o que é ifrs?, 2014 Estados Unidos da América, Tradução livre. disponível em: http://www.ifrs.com/updates/aicpa/ifrs_faq.html\#q1. Acesso em: 26 de setembro. 2014

INTERNATIONAL FINANCIAL REPORTING STANDARDS (IFRS), 2008. Normas Internacionais de Contabilidade. Disponível em: http://www.bradescori.com.br Acesso em: 16 out. 2010. 
IUDÍCIBUS, S. de. Teoria da contabilidade. 10. ed. São Paulo: Atlas, 2010.

LEMES, S.; SILVA, M. G. A experiência de empresas brasileiras na adoção das IFRS. Contabilidade Vista \& Revista, Belo Horizonte, v. 18, n. 3, p. 37- 58, julho/setembro 2007.

LUCENA, W. G. L.; LEITE, D. C. de C.; NIYAMA, J. K. Contabilidade Internacional e os Desafios da Harmonização Mundial. Disponível em: http://veredas.favip.edu.br/index.php/veredas/article/viewFile/5/4 Acesso em: 07 set. 2011.

MADEIRA, G. J. S.; ALMEIDA C. B. A.; FABIANA, L. Harmonização de normas contábeis: um estudo sobre as divergências entre normas contábeis internacionais e seus reflexos na contabilidade brasileira. Revista Mineira de Contabilidade. Belo Horizonte, Ano V, n. 16, 4. trim. 2004.

MADEIRA, G. J. S. Harmonização de Normas Contábeis: um estudo sobre a divergências entre normas contábeis internacionais e seus reflexos na contabilidade brasileira. Revista Brasileira de Contabilidade, jul./ago. 2004.

MALAQUIAS, Rodrigo Fernandes. Disclosure de instrumentos financeiros segundo as normas internanacionais de contabilidade: evidências empíricas de empresas brasileiras. 2008. 163 f. Dissertação (Mestrado em Ciências Sociais Aplicadas) - Universidade Federal de Uberlândia, Uberlândia, 2008.

MARCONI, Marina de Andrade; LAKATOS, Eva Maria. Técnicas de Pesquisa. 2. ed. São Paulo: Atlas, 1990.

MARION, José Carlos; IUDÍCIBUS, Sergio de. Introdução à teoria da contabilidade. 4. Ed. São Paulo: Atlas, 2006.MEIRELlES JUNIOR, Julio Candido de; MEIRELLES, Camyla D'Elyz do Amaral. A busca pela harmonização das normas internacionais de contabilidade. Revista Mineira de Contabilidade, Belo Horizonte, n. 33, p. 6-15, jan./mar. 2009.

MEIRELLES JUNIOR, J. C. de. Normas internacionais de contabilidade: desafios para implantação. Disponível em: http://docplayer.com.br/6571937-Normas-internacionais-de-contabilidade-desafios-paraimplantacao-resumo.html. Acesso em: 21/07/2016.

MIRZA, Abbas Ali; HOLT, Graham J.; ORRELL, Magnus. IFRS - International Financial Reporting Standards: Workbook and Guide. Wiley: 2006.

MISSAGIA, L. R.; VELTER, F. Manual de contabilidade. $4^{\text {a }}$ ed. Rio de Janeiro: Campus - Elsevier, 2005.

NAGATSUKA, Divane Alves da Silva; TELES, Egberto Lucena. Manual de contabilidade introdutória. São Paulo: Thompson, 2002.NIYAMA, Jorge Katsumi. Contabilidade internacional. São Paulo: Atlas, 2005.NIYAMA, J. K. Contabilidade internacional. 1. ed. São Paulo: Atlas, 2007.

NIYAMA, J. K.; SILVA, C. A. T. Teoria da Contabilidade. São Paulo: Atlas, 2008. 309p. 
NIYAMA, J. K.. Contabilidade internacional. 1. ed. São Paulo: Atlas, 2009. p. 38 - 41.

NIYAMA, J. K.;RODRIGUES, J. M. Análise das demonstrações contábeis das companhias listadas na Bovespa: uma abordagem sobre os impactos decorrentes das modificações introduzidas pela Lei $\mathrm{n}^{\circ}$ 11.638/07. Revista Brasileira de Contabilidade, São Paulo, n. 25/38, p. 25, maio/jun. 2010.

OLIVEIRA, Alexandre Martins Silva de; [ et al.]. Contabilidade Internacional: Gestão de riscos, governança corporativa e contabilização de derivativos. São Paulo: Atlas, 2008.

PADOVEZE, C. L. Contabilidade gerencial: um enfoque em um sistema de informação contábil. São Paulo: Atlas, 1996.

PENA, R. Fluxos da sociedade global. In: REDE OMNIA. Mundo Educação. Website. Disponível em: $<$ http://mundoeducacao.bol.uol.com.br/geografia/fluxos-sociedade-global.htm>. Acesso em: 10 maio 2017.

PINHEIRO, C. F. R., Azevedo, G. M. C. \& Cruz, S. N. S. R. A. (2013). Do POC ao SNC: Evolução e Aspetos Diferenciadores. Revista Portuguesa de Contabilidade, 111 (10), 1 - 24.

PORTER, M. Estratégias competitivas: técnicas para a análise da indústria e da concorrência. Rio de Janeiro: Campus, 1986. ROSA, Paulo Moreira da. Contabilidade no mercosul: profissão contábil, normas e praticas contábeis, demonstrações patrimoniais, composição e avaliação de elementos do ativo. São Paulo: Atlas, 1999.

REZAEE, Zabihollah; SMITH, L. Murphy; SZENDI, Joseph Z. Convergence in accounting standards: insights from academicians and practitioners. Advances in Accounting, 26, n. 1, p.142-154, jun., 2010.

SILVA, C. B. A.; MADEIRA, G. J. Gestão de estoques e lucro da empresa. Contabilidade Vista \& Revista, v. 15, n. 2, p. 41-52, 2004

TEODORO, A. F. de O. ; TEODORO, J. C. ; MACEDO, D. L. ; COSTA, V. N. ; TOSTA, D. S. . Um Estudo Empírico sobre a Convergência das Normas Internacionais Correlacionadas a Tríade: Ensino, Pesquisa e Extensão. In: X Simpósio de Excelência em Gestão e Tecnologia - SEGeT, 2013, Resende. Anais do X Simpósio de Excelência em Gestão e Tecnologia - SEGeT - SEGeT, 2013.

WEFFORT, E. F. J. O Brasil e a harmonização contábil internacional. São Paulo: Atlas, 2005.

ZURN, M. Globalization and Global Governance. In: CARLSNAES, W. et al (Ed.), Handbook of International Relations. SAGE Publications, second edition, 2013.

${ }^{[1]}$ Graduado em Ciências Contábeis pela Universidade Federal do Piauí.

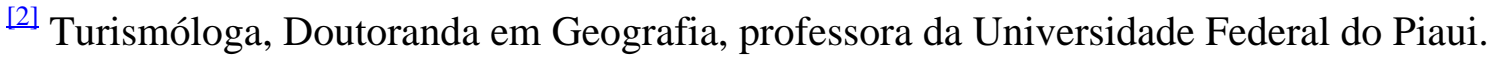

[3] Advogado, Doutor em Direito, Professor de Direito Comercial da UESB - Universidade Estadual do 
Sudoeste da Bahia; Professor de Direito Tributário da FAINOR - Faculdade Independente do Nordeste; Professor de Direito Tributário da FIJ - Faculdades Integradas de Jequié.

[4] Teóloga, Doutora em Psicanálise Clínica. Atua há 15 anos com Metodologia Científica ( Método de Pesquisa) na Orientação de Produção Científica de Mestrandos e Doutorandos. Especialista em Pesquisas de Mercado e Pesquisas voltadas a área da Saúde.

\section{PUBLIQUE SEU ARTIGO CIENTÍFICO EM:}

https://www.nucleodoconhecimento.com.br/enviar-artigo-cientifico-para-submissao 